Article

\title{
Investigation of the Microwave Absorption of Asphalt Mixtures Containing Magnetite Powder
}

\author{
Bowen Guan ${ }^{1, *}$, Jianan Liu ${ }^{1, *} \mathbb{C}$, Hua Zhao ${ }^{2}$, Jiayu $\mathrm{Wu}^{1}{ }^{1}$, Jingyi Liu ${ }^{1}$ and Fa Yang ${ }^{1,3}$ \\ 1 School of Materials Science and Engineering, Chang'an University, Xi'an 710061, China; \\ wjy1991@chd.edu.cn (J.W.); 2017031003@chd.edu.cn (J.L.); 2019231019@chd.edu.cn (F.Y.) \\ 2 School of Civil Engineering and Architecture, Nanchang University, Nan Chang 330031, China; \\ zhaohua@ncu.edu.cn \\ 3 Yunnan Communications Investment \& Construction Group Co., Ltd., Kunming 650228, China \\ * $\quad$ Correspondence: bguan@chd.edu.cn (B.G.); ljn1996@chd.edu.cn (J.L.); Tel.: +86-29-8233-4849 (B.G.)
}

Received: 29 October 2019; Accepted: 26 November 2019; Published: 2 December 2019

\begin{abstract}
This article is intended to investigate the microwave heating performance of asphalt mixtures containing magnetite powders (MPAM). For this purpose, the surface temperatures of asphalt mixtures containing different dosages of magnetite powders were measured during microwave heating. The low-temperature bending test and water sensitivity test were also conducted to evaluate the performance of MPAM. Heating rate and reflection loss of different thicknesses of MPAM were determined using a microwave heating test and arch reflectivity test, respectively. The results showed that because its main components are triiron tetroxide and iron oxide, which have excellent microwave-absorbing properties, magnetite powders can be used as microwave absorbers to improve the ability of microwave absorption and increase the heating rate of asphalt mixtures. The heating rate of the asphalt mixtures increased with the increase of the amount of magnetite powder. The addition of magnetite powder improved the low-temperature properties of the asphalt mixture, but it reduced the water stability of the asphalt mixture. Considering that the microwave-absorbing asphalt mixture used for melting snow and ice should have good water stability, the recommended dosage of magnetite powders was $60 \%$. The microwave-absorbing properties of MPAM were related to its thickness in the pavement structure and frequency of microwaves. In order to greatly enhance the absorbing efficiency, future work should be focused on matching thickness and matching frequency.
\end{abstract}

Keywords: asphalt mixture; magnetite powders; microwave absorbance; heating; snow melting; deicing

\section{Introduction}

Timely removal of snow and ice from pavement surfaces is essential for traffic safety in the winter [1]. Mechanical snow removal and snow melting agents are often used to remove snow and ice from pavement surfaces by road maintenance departments [2]. However, mechanical snow removal faces difficulties when removing snow compaction and can easily cause surface damage. Although snow melting agents, such as sodium chloride, calcium chloride, and magnesium chloride, are better at removing snow and ice, they cause corrosion to vehicles and concrete structures [3,4]. Considering the defects of traditional snow melting and deicing methods, it is necessary to develop a new, efficient, and clean method for removing snow and ice.

Microwave deicing uses microwaves to rotate polar molecules in the asphalt mixture to generate thermal energy in order to melt and separate the ice layer in the snowpack from the pavement surface [5-8]. Compared to traditional snow melting and deicing methods, microwave deicing technology has the advantages of high deicing efficiency and being environmentally friendly [9]. However, there is only a small number of microwave-absorbing components in asphalt mixtures [10]. 
Most of this energy is transmitted or reflected in the asphalt mixture, and only a small portion of the energy is absorbed in the asphalt mixture [11]. Because of this, microwave deicing technology faces the problem of excessive energy consumption, which limits the promotion and application of this technology [12-14]. In order to improve the microwave-absorbing ability of asphalt mixtures and reduce the energy consumption of microwave deicing, various kinds of microwave absorbers are used in asphalt mixture. Notani [15] found that carbon fiber modified asphalt concrete can melt dense layers of snow and ice and be used in critical areas such as airfields. Sun [16] studied the self-healing performance of asphalt mixtures containing steel fibers with microwave heating. Zhang [17] evaluated the microwave deicing performance of an asphalt mixture made with low-grade pyrite cinder synthetic ceramics. Magnetite is a rock mineral, whose main component is $\mathrm{Fe}_{3} \mathrm{O}_{4}$, which has ferromagnetic and semi-conductive properties, and it is widely distributed throughout the world $[18,19]$. Compared with the other microwave absorbers mentioned previously, magnetite powders are easy to obtain and are inexpensive. The microwave-absorbing performance of an asphalt mixture may be improved by the addition of magnetite powders (MPAM). However, few studies have reported on this.

In this paper, the microwave-absorbing property of asphalt mixtures containing magnetite powders was investigated. The surface temperatures of asphalt mixtures containing different dosages of magnetite powders were measured during microwave heating. The low-temperature bending test and water sensitivity test were also conducted to evaluate the performance of MPAM. Heating rate and reflection loss of different thickness of MPAM were determined using a microwave heating test and arch reflectivity test, respectively. According to the test results, the optimum content of magnetite powders in asphalt mixtures and the reasonable thickness of MPAM in the pavement structure were determined. In addition, the microwave heating mechanism of MPAM was also discussed.

\section{Materials and Methods}

\subsection{Materials}

Asphalt (90\#, SK energy Co., Ltd., Seoul, Korea) was used as the binder, and its properties are shown in Table 1. Limestone (Tie Cheng Co., Ltd., Xi'an, China) was used as an aggregate, and its properties are shown in Table 2. Magnetite powders (Tie Cheng Co., Ltd., Xi'an, China) and limestone powders (Tie Cheng Co., Ltd., Xi'an, China) were used as the fillers, and their physical properties are summarized in Table 3.

Table 1. Properties of 90\# asphalt.

\begin{tabular}{cccc}
\hline Test Properties & Unit & Test Results & Test Basis \\
\hline Needle penetration $\left(25^{\circ} \mathrm{C}\right)$ & $0.1 \mathrm{~mm}$ & 83.1 & ASTM D5-19 [20] \\
Soften point & ${ }^{\circ} \mathrm{C}$ & 47.4 & ASTM D36-14 [21] \\
Ductility $\left(15^{\circ} \mathrm{C}, 5 \mathrm{~cm} / \mathrm{min}\right)$ & $\mathrm{cm}$ & $>100$ & ASTM D113-17 [22] \\
Wax content & $\%$ & 1.74 & ASTM D3344-90 [23] \\
Specific gravity & - & 1.030 & ASTM D70-18 [24] \\
Flash point & ${ }^{\circ} \mathrm{C}$ & 304 & ASTM D92-18 [25] \\
\hline & $\mathbf{R T F O T ~}\left(\mathbf{1 6 3}{ }^{\circ} \mathbf{C}, \mathbf{7 5} \mathbf{~ m i n}\right)$ & \\
\hline Mass change & $\%$ & 0.05 & ASTM D2872-19 [26] \\
Penetration ratio $\left(25^{\circ} \mathrm{C}\right)$ & $\%$ & 82.7 & ASTM D5-19 \\
Ductility $\left(10{ }^{\circ} \mathrm{C}\right)$ & $\mathrm{cm}$ & 29.3 & ASTM D113-17 \\
\hline
\end{tabular}

Table 2. Properties of limestone aggregate.

\begin{tabular}{cccc}
\hline Crushing Value (\%) & Los Angeles Wear value (\%) & Density (g/cm $\left.\mathbf{c m}^{\mathbf{3}}\right)$ & Water Absorption (\%) \\
\hline 18.4 & 20.7 & 2.639 & 0.70 \\
\hline
\end{tabular}


Table 3. Physical properties of magnetite powder.

\begin{tabular}{ccccc}
\hline Filler & Density $\left(\mathrm{g} / \mathbf{c m}^{\mathbf{3}}\right)$ & Water Content (\%) & Hydrophilic Coefficient & $\mathbf{0 . 0 7 5} \mathbf{~ m m ~ P e r c e n t ~ P a s s i n g ~ ( \% ) ~}$ \\
\hline Magnetite powder & 4.6 & 1.1 & 1.43 & 75.7 \\
Limestone filler & 2.79 & 0.5 & 0.56 & 77.2 \\
\hline
\end{tabular}

\subsection{Sample Preparation}

Magnetite powder was added to the base asphalt binder instead of limestone powder by volumes of $0 \%, 20 \%, 40 \%, 60 \%, 80 \%$, and $100 \%$. The optimum asphalt contents of asphalt mixtures containing $0 \%, 20 \%, 40 \%, 60 \%, 80 \%$, and $100 \%$ magnetite powder are $4.7 \%, 4.6 \%, 4.6 \%, 4.5 \%, 4.5 \%$, and $4.4 \%$, respectively. AC-13 gradation of the aggregate is shown in Figure 1.

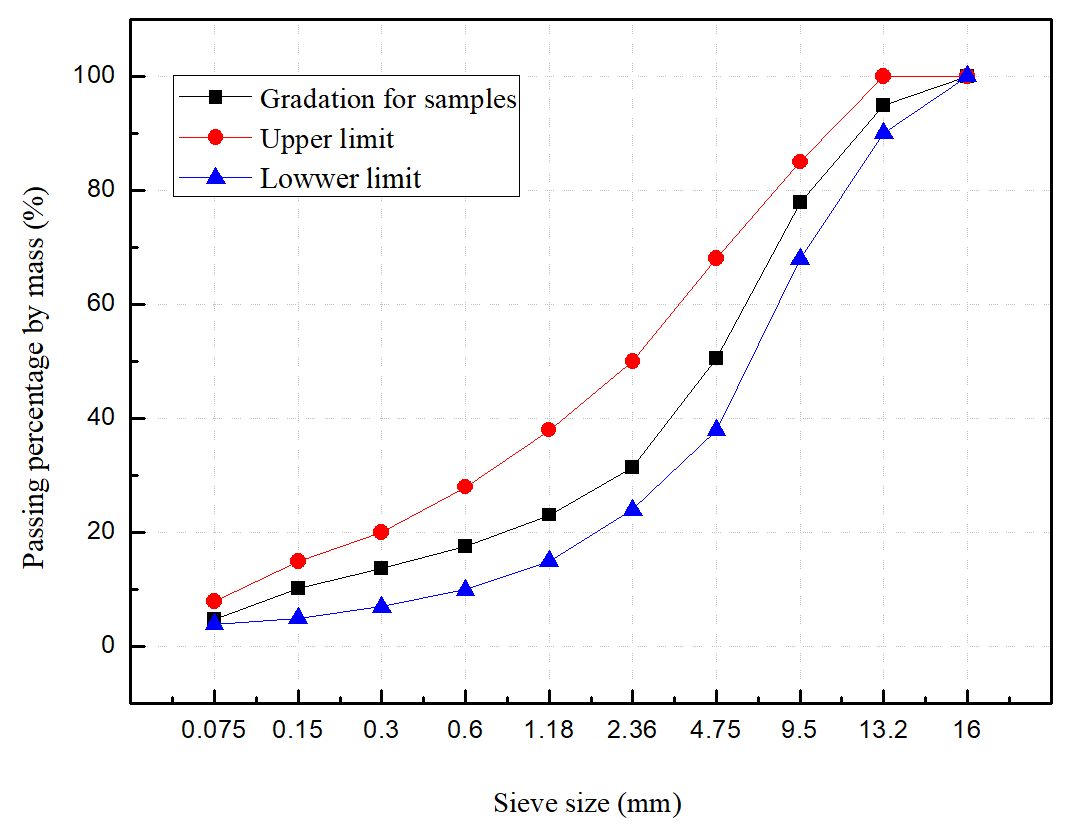

Figure 1. AC-13 gradation of the aggregate.

At first, aggregate and mineral fillers were dried at $110^{\circ} \mathrm{C}$ for $6 \mathrm{~h}$. The asphalt was heated in an oven at $150{ }^{\circ} \mathrm{C}$. Then, the aggregate, asphalt, magnetite powders, and limestone powders were added in the mixer in sequence at a temperature of $150{ }^{\circ} \mathrm{C}$. The asphalt mixture was prepared at a speed of $75 \mathrm{r} / \mathrm{min}$ for $3 \mathrm{~min}$. The prepared mixture was placed in molds by the compaction method. After curing for $24 \mathrm{~h}$, specimens were demolded from the molds and cut using a diamond disc. There were three sizes of specimens. One was $101.6 \pm 0.25 \mathrm{~mm}$ in diameter and $63.5 \pm 1.35 \mathrm{~mm}$ in height and was used for microwave heating and freeze-thaw splitting tests. The second was $300 \mathrm{~mm} \times 300 \mathrm{~mm} \times$ $70 \mathrm{~mm}$ and used for the reflection loss test. The last was $250 \mathrm{~mm} \times 30 \mathrm{~mm} \times 35 \mathrm{~mm}$ and was used for the bending test. In order to study the thickness of MPAM on the microwave-absorbing performance, compacted specimens with $0,3,5$, and $7 \mathrm{~cm}$ thicknesses of MPAM were prepared, which is shown in Figure 2. Preparation of the specimens of dual material was divided into the following two steps. At first, the base layer of the ordinary asphalt mixture was compacted using a drop hammer 50 times on each side. Then, the loose MPAM was also placed on the base layer and compacted using the drop hammer 50 times on each side. The total height of specimens was controlled at $70 \pm 1 \mathrm{~mm}$. 

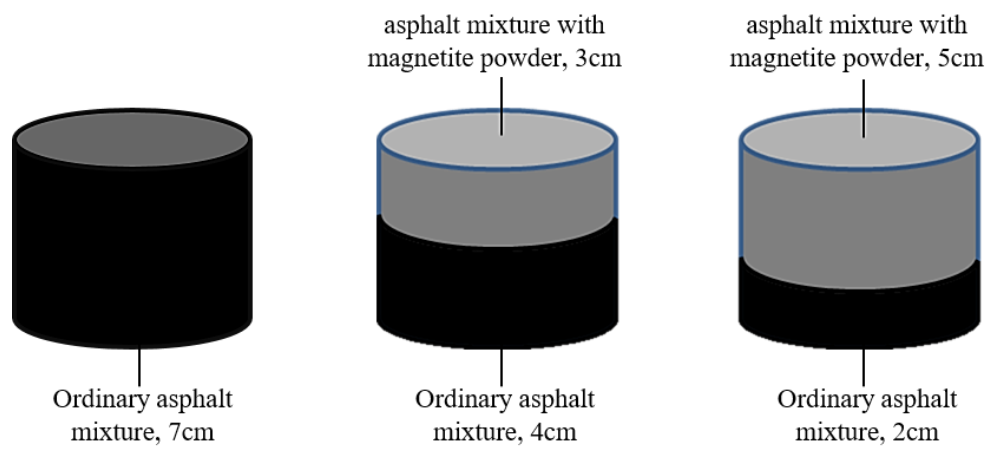

asphalt mixture with

magnetite powder, $7 \mathrm{~cm}$

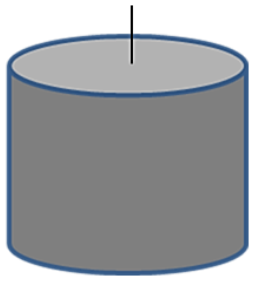

Figure 2. Asphalt mixture with different thicknesses of asphalt mixtures containing magnetite powders (MPAM).

\subsection{Microwave Heating Test}

An infrared temperature instrument (Fluke Corporation, Everett, WA, USA) was used to test the electromagnetic wave (EM) absorption performance of the asphalt mixture. The prepared mixtures were heated in a Microwave Heating (MH) device (Galanz, Shunde, China). It was noted that as microwave heating is of volumetric type, the surface was not the hottest point in the heated object. However, for the deicing methodology using microwaves, deicing efficiency is closely related to surface temperature. Therefore, surface temperature was tested in this paper. The initial surface temperature of the mixture was measured before heating. The temperatures of the Marshall specimens were measured every $2 \mathrm{~min}$ after the start of heating. Heating the asphalt mixture was done with a microwave oven $(800 \mathrm{~W}$ power, $2.45 \mathrm{GHz}$ ). When the surface temperature of specimens rose to $200^{\circ} \mathrm{C}$, heating was stopped. Then, the heating rate and the variation of temperature with heating time of the mixture were obtained. Five spots of each surface were tested.

\subsection{Bending Test}

The low-temperature property of the asphalt mixture was evaluated by a 3-point bending test at a low temperature in terms of JTG E20-2011 [27]. The loose asphalt mixture was compacted into a $300 \mathrm{~mm} \times 300 \mathrm{~mm} \times 50 \mathrm{~mm}$ slab and sawed into beams $(250 \mathrm{~mm} \times 30 \mathrm{~mm} \times 35 \mathrm{~mm})$ that each spanned lengths of $200 \mathrm{~mm}$. The test temperature was $10^{\circ} \mathrm{C}$, and the loading rate was $50 \mathrm{~mm} / \mathrm{min}$.

$$
R_{\mathrm{B}}=\frac{3 L P_{\mathrm{B}}}{2 b h^{2}}
$$

where $R_{\mathrm{B}}$ is the splitting strength of the specimen (MPa); $L$ is the length of the specimen (200 $\mathrm{mm}$ ); $P_{\mathrm{B}}$ is maximum load when the specimen is broken $(\mathrm{N}) ; b$ is the width of the specimen's cross-section $(\mathrm{mm})$; and $h$ is the height of the specimen's cross-section (mm).

\subsection{Freeze-Thaw Splitting Test}

Water sensitivity of the asphalt mixture was evaluated by a freeze-thaw splitting test according to T0716 of JTG E20-2011 [27]. In this test, the Marshall specimens with 50 hammer blows on each side were used. The specimens were immersed in water in vacuum conditions and were then put into a plastic bag with $10 \mathrm{~mL}$ water and transferred to a chamber at a temperature of $-18 \pm 2{ }^{\circ} \mathrm{C}$ for $16 \pm 1 \mathrm{~h}$. After freezing, specimens were kept in water at a temperature of $60 \pm 5^{\circ} \mathrm{C}$ for $24 \mathrm{~h}$ without a plastic bag. After the freeze-thaw treatment, specimens were placed in water at a temperature of $25^{\circ} \mathrm{C}$ for $2 \mathrm{~h}$. The tensile strength ratio (TSR) can be calculated with Equations (2)-(4).

$$
R_{T 1}=\frac{0.006287 P_{T 1}}{h_{1}}
$$




$$
\begin{gathered}
R_{T 2}=\frac{0.006287 P_{T 2}}{h_{2}} \\
\mathrm{TSR}=\frac{\bar{R}_{T 2}}{\bar{R}_{T 1}} \times 100
\end{gathered}
$$

where $R_{T 1}$ is the splitting strength of the specimen set without freezing and thawing. $R_{T 2}$ is the splitting strength of the specimens after freezing and thawing (MPa). $P_{T 1}$ is the test load value of a set of specimens without freeze-thaw cycles $(\mathrm{N}) . P_{T 2}$ is the test load value of a set of specimens with freeze-thaw cycles $(\mathrm{N})$.

\subsection{Reflection Loss Test}

In this paper, the reflection loss of materials was measured with the arch method testing system according to the standard measurement methods for reflectivity of radar-absorbing materials (GJB2038A-2011) [28]. The arch method testing system is shown in Figure 3. The specimen was placed on the shelf, and the reflection loss test was measured at frequencies from 2 to $14 \mathrm{GHz}$.

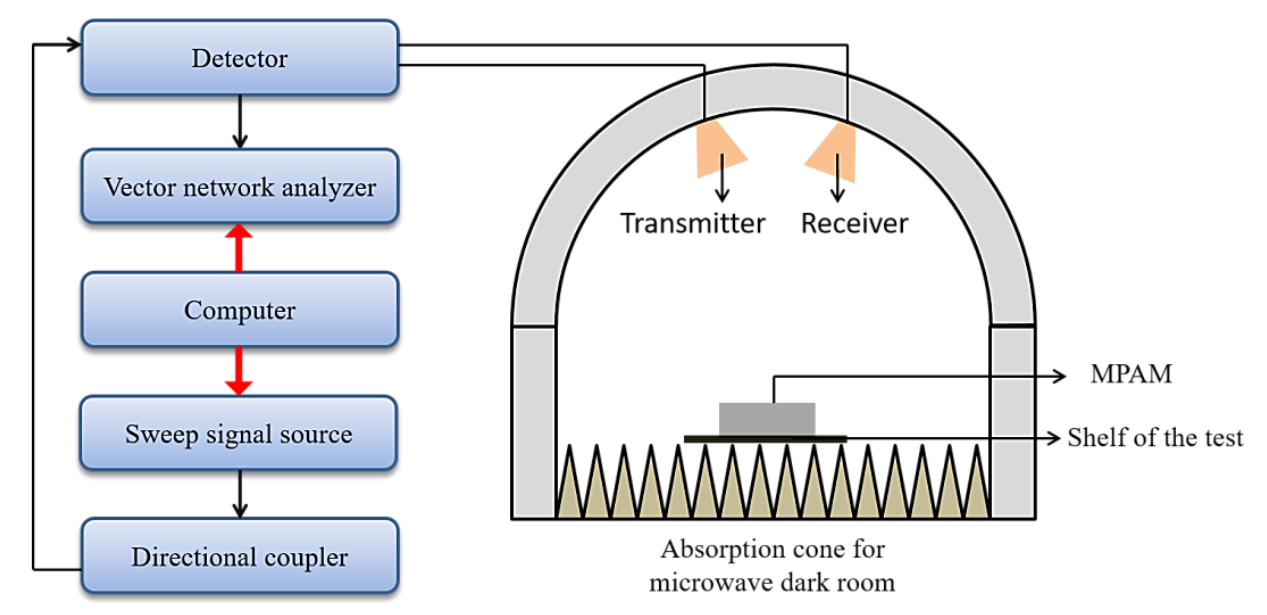

Figure 3. The schematic diagram of the arch method testing system.

\subsection{Microscopy and X-ray Diffraction (XRD) Test}

The morphologies of the magnetite powder and the limestone filler were analyzed with a Quanta FEG 250 Scanning Electron Microscope (SEM, S-4800; Hitachi, Tokyo, Japan). The magnetite powder was investigated with X-ray diffraction (XRD, Bruker Corporation, New York, NY, USA). The test voltage was $40 \mathrm{kV}$.

\section{Results and Discussion}

\subsection{Effect of Magnetite Powder Dosage on the Microwave Heating Performance}

Figure 4 shows the surface temperature of MPAM containing different dosages of magnetite powders during microwave heating. It can be seen in Figure 4 that the surface temperature of MPAM showed an increasing trend with the increase of microwave heating time. Table 4 shows a positive linear relationship between surface temperature and microwave heating time in MPAM containing different dosages of magnetite powders. The relationship between surface temperature and microwave heating time can be described by Equation (5).

$$
T=K t+T_{i}
$$

where $T$ is the surface temperature $\left({ }^{\circ} \mathrm{C}\right), t$ is the microwave heating time (min), $T_{i}$ is room temperature $\left({ }^{\circ} \mathrm{C}\right)$, and $K$ is the heating rate $\left({ }^{\circ} \mathrm{C} / \mathrm{min}\right)$. 


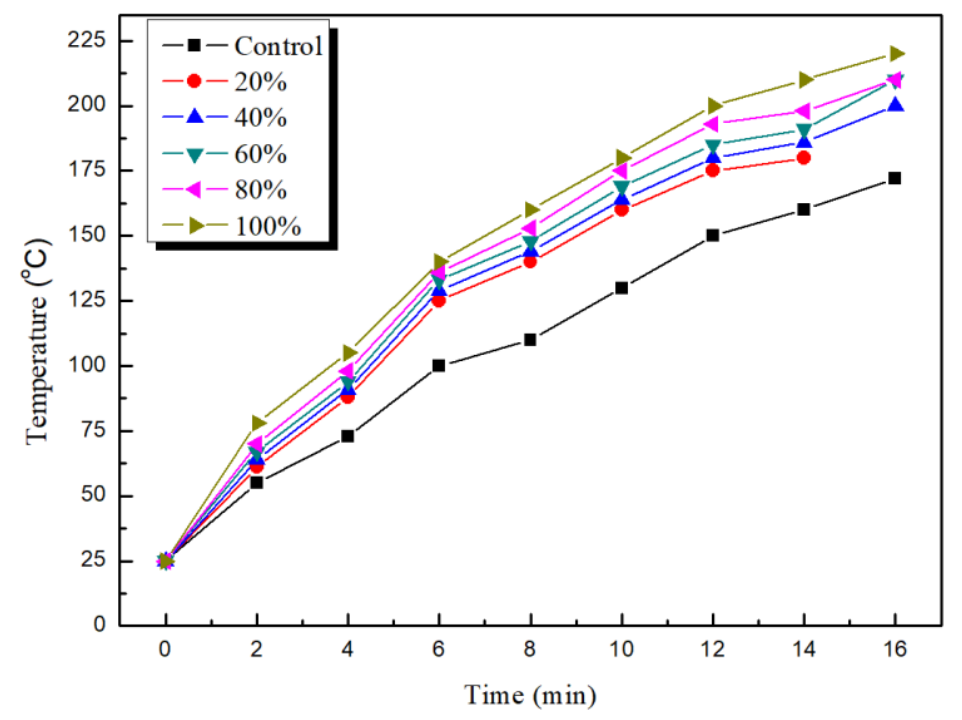

Figure 4. Surface temperature of MPAM during microwave heating.

Table 4. The relationship between surface temperature and heating time.

\begin{tabular}{cccc}
\hline Dosage of Magnetic Powder (\%) & Regression Equation & $\boldsymbol{K}$ & $\boldsymbol{R}^{\mathbf{2}}$ \\
\hline 0 & $T=10.02 t+25$ & 10.02 & 0.994 \\
20 & $T=12.52 t+25$ & 12.52 & 0.987 \\
40 & $T=12.79 t+25$ & 12.79 & 0.984 \\
60 & $T=13.03 t+25$ & 13.03 & 0.984 \\
80 & $T=13.44 t+25$ & 13.44 & 0.981 \\
100 & $T=14.16 t+25$ & 14.61 & 0.981 \\
\hline
\end{tabular}

It can be seen in Table 4 that the heating rate $(K)$ increased with increasing dosages of magnetite powders. Compared with traditional asphalt mixture, the heating rate of MPAM containing $20 \%$, $40 \%, 60 \%, 80 \%$, and $100 \%$ dosages of magnetite powders increased by $24.9 \%, 27.6 \%, 30.0 \%, 34.1 \%$, and $45.8 \%$, respectively. $R^{2}$ is the correlation coefficient. This phenomenon clearly shows that the addition of magnetite powders as microwave absorbers improved the microwave heating performance of the asphalt mixture. When the pavement surface is heated to the same temperature, MPAM can save more energy than traditional asphalt mixtures.

To gain a better understanding of the influence of magnetite powders on the microwave heating performance of MPAM, XRD analyses of magnetite powders were carried out. The results are shown in Figure 5. The main mineral components of the magnetite powders were determined using Jade 5.0 software. The mineral content was calculated with X' Pert High Score Plus software (Version 2.0). Figure 5 shows the main components of magnetite powders from magnetite tailings, which are magnetite $\left(\mathrm{Fe}_{3} \mathrm{O}_{4}\right)$, hematite $\left(\mathrm{Fe}_{2} \mathrm{O}_{3}\right)$, and quartz $\left(\mathrm{SiO}_{2}\right)$. The proportions of $\mathrm{Fe}_{3} \mathrm{O}_{4}, \mathrm{Fe}_{2} \mathrm{O}_{3}$, and $\mathrm{SiO}_{2}$ in magnetite powders are $47.5 \%, 24.4 \%$, and $28 \%$, respectively. Some studies have reported that, based on the heating rate, $\mathrm{Fe}_{3} \mathrm{O}_{4}, \mathrm{Fe}_{2} \mathrm{O}_{3}$, and $\mathrm{SiO}_{2}$ are hyperactive, active, and inactive, respectively. From the perspective of photon transition, the microwave absorption process of magnetite particles is a rotating molecular mechanism that is related to its own structure [29]. The structure of $\mathrm{Fe}_{3} \mathrm{O}_{4}$ is an inverse spinel in which an oxygen atom forms a face-centered cubic lattice densely packed with iron atoms occupying tetrahedral and octahedral positions, which makes the magnetite have ferromagnetic and semi-conductive properties [7]. Therefore, higher dosages of magnetite powder resulted in a better microwave absorption ability of MPAM. The results of the microwave heating test also proved this. Figure 6 shows the heating process of MPAM with microwave heating. When microwaves irradiate MPAM, microwave-absorbing components in asphalt mixtures, especially magnetite powders and 
metal oxide in the aggregate, absorb microwave energy and convert it into heat energy. Subsequently, heat energy is transferred to the entire MPAM. Finally, the temperature of MPAM increases.

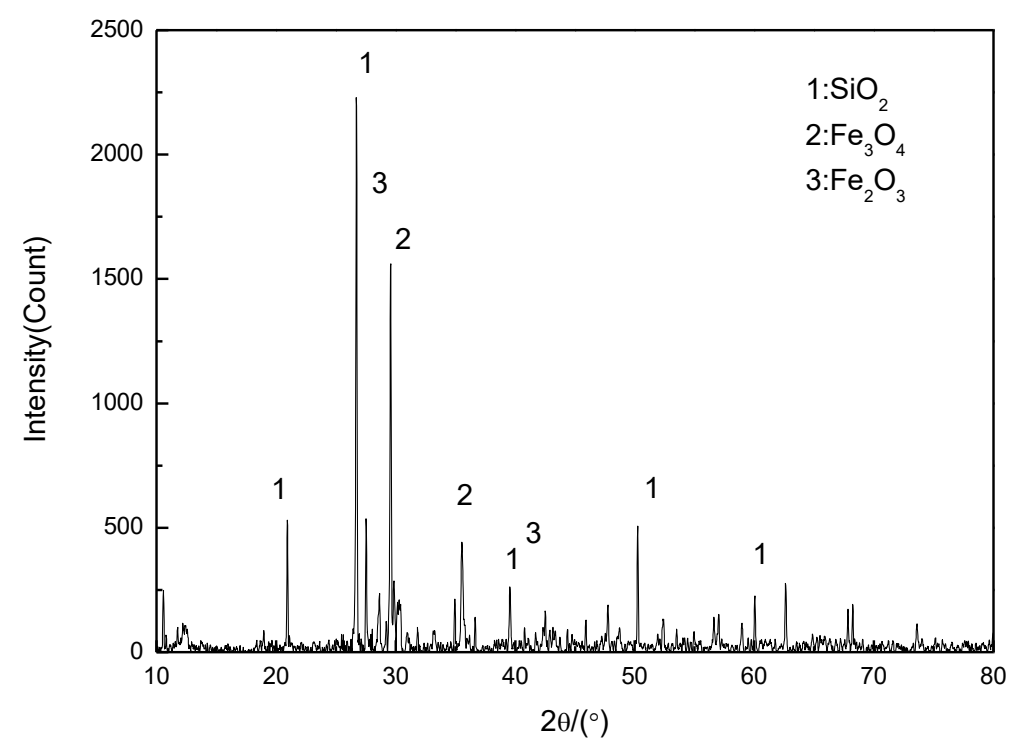

Figure 5. XRD pattern of magnetite powder Microwave

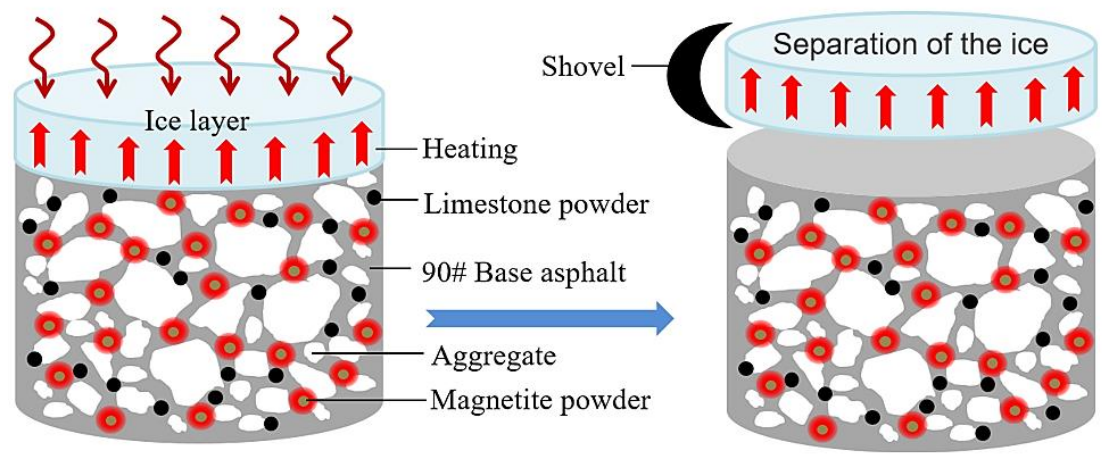

Figure 6. Microwave heating deicing process.

\subsection{Effect of Magnetite Powder Dosage on Road Performance}

MPAM is used for melting snow and ice. Therefore, it should have excellent crack resistance at a low temperature and good water sensitivity.

\subsubsection{Low-Temperature Properties}

Low-temperature properties of the asphalt mixture were evaluated with a 3-point bending test. The evaluation indexes of asphalt mixtures at a low temperature are the maximum bending tensile strength, the maximum tensile strain, and the bending stiffness modulus. The relationship between the maximum bending stress of the asphalt mixture and the content of magnetite powders is shown in Figure 7 . The error bars represent the standard deviation of the data set. It shows that the maximum bending stress of MPAM with different dosages of magnetite at $10^{\circ} \mathrm{C}$ was $11.12,12.66,12.27,12.45,12.56$, and $11.64 \mathrm{MPa}$, respectively. The addition of magnetite powders can slightly increase the maximum bending stress at a low temperature. Figure 8 shows that with the increasing dosage of magnetite powders, the maximum tensile strain increased continuously, which indicates that the addition of magnetite powders had a positive impact on the low-temperature deformation capacity. Although the bending stiffness modulus of the asphalt mixture increased when a $20 \%$ dosage of the magnetite powders was added, the overall 
trend was that the bending stiffness modulus decreased as the amount of magnetite powders was increased. It can be seen clearly that the maximum tensile strain increased with an increasing dosage of magnetite powders. The reason may be that the surface of the magnetite powder is more "clean" than that of limestone filler (Figures 9 and 10), which results in less absorption of light asphalt fractions. The "excess" free asphalt is beneficial to reduce the bending stiffness modulus of the asphalt mixture to a certain extent and improves its flexibility. Therefore, the low-temperature crack resistance of the asphalt mixture is improved with the addition of magnetite powder [30].

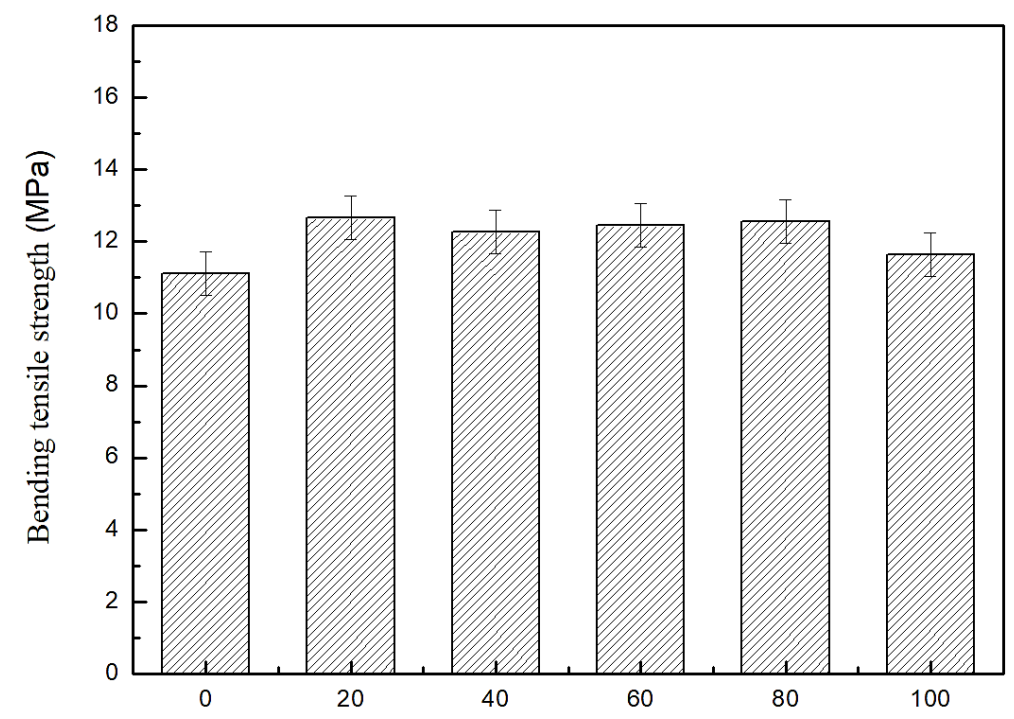

Figure 7. Bending tensile strength of the mixture.

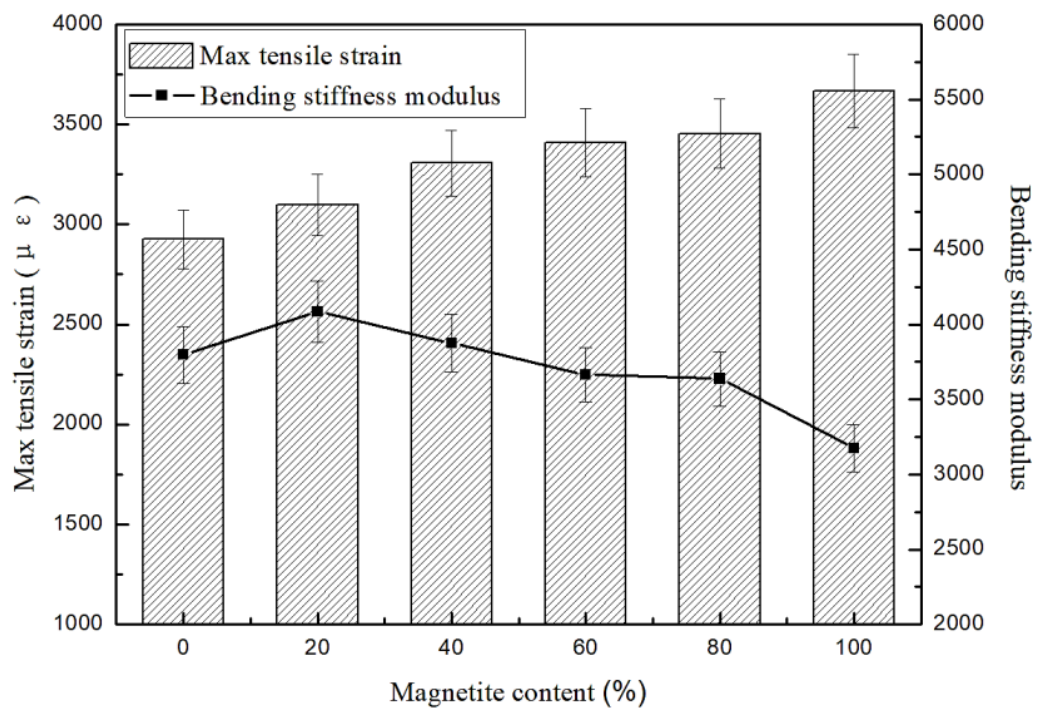

Figure 8. Max tensile strain and bending stiffness modulus of the mixture. 

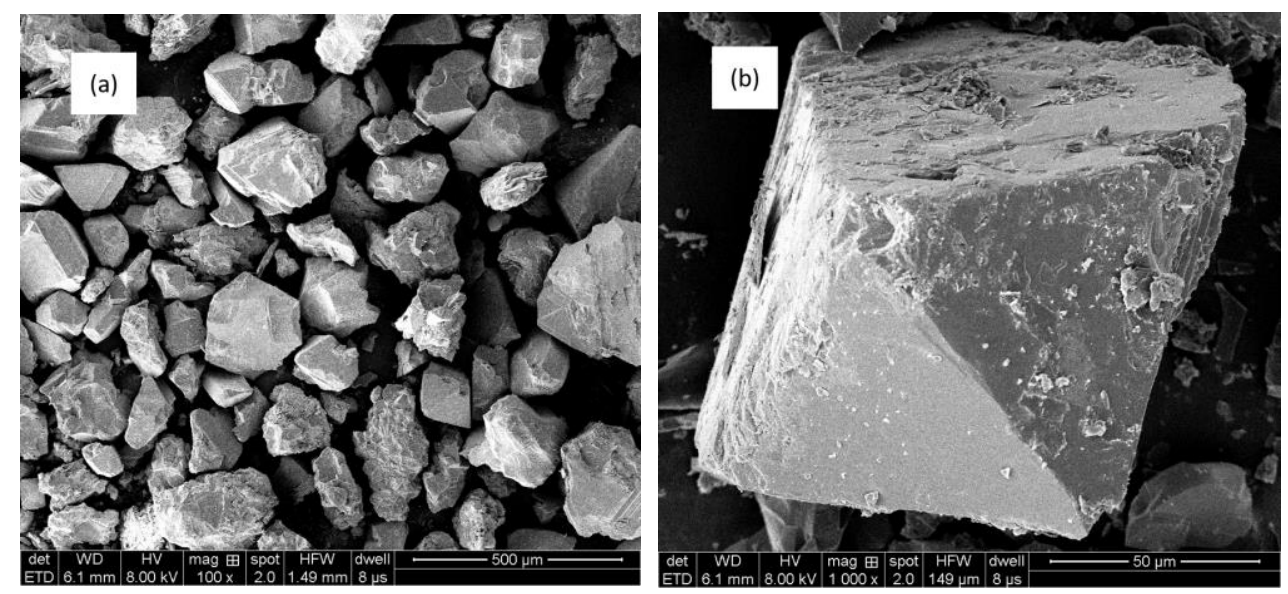

Figure 9. SEM image of the magnetite powder (a) 100 times and (b) 1000 times.
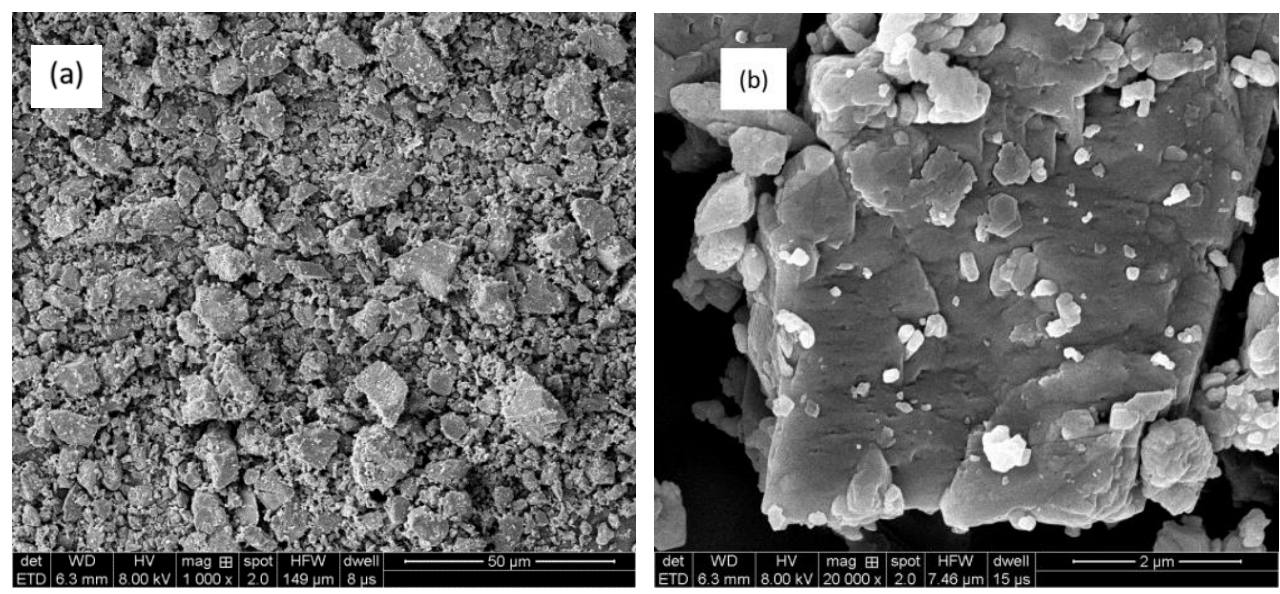

Figure 10. SEM image of the limestone filler (a) 1000 times (b) 20,000 times.

\subsubsection{Water Sensitivity}

Figure 11 shows the tensile strength ratio (TSR) of MPAM with different dosages of magnetite powders. The value of TSR decreased with the increase of the dosage of magnetite powders. It indicates that the addition of magnetite powders reduced the water stability of the asphalt mixture. The function of mineral powders is to fill the voids in the aggregate skeleton and make the asphalt mixture denser to improve the cohesion of the asphalt binder and the stability of the mixture. The surface structure of limestone powder is rough, the particle size is small, and the surface area is large, as shown in Figure 10. These characteristics increase the contact area between asphalt and filler, and it is easier to absorb and stabilize the interface [31]. Limestone powder with a smaller particle size is beneficial for making the mixture denser. Additionally, the limestone powder contains more calcite $\left(\mathrm{CaCO}_{3}\right)$, which can interact with acidic components in the asphalt to improve the cohesion of the asphalt binder [32]. The use of magnetite powder instead of limestone powder as a mineral filler is not conducive to the water stability of the asphalt mixture. Therefore, it is necessary to control the amount of magnetite powder in the asphalt mixture. According to the Chinese specification (JTG F40-2004) [33], the value of TSR should be greater than $80 \%$. In order to meet water stability requirements and maintain the microwave heating performance of MPAM, the recommended dosage of magnetite powders is $60 \%$. 


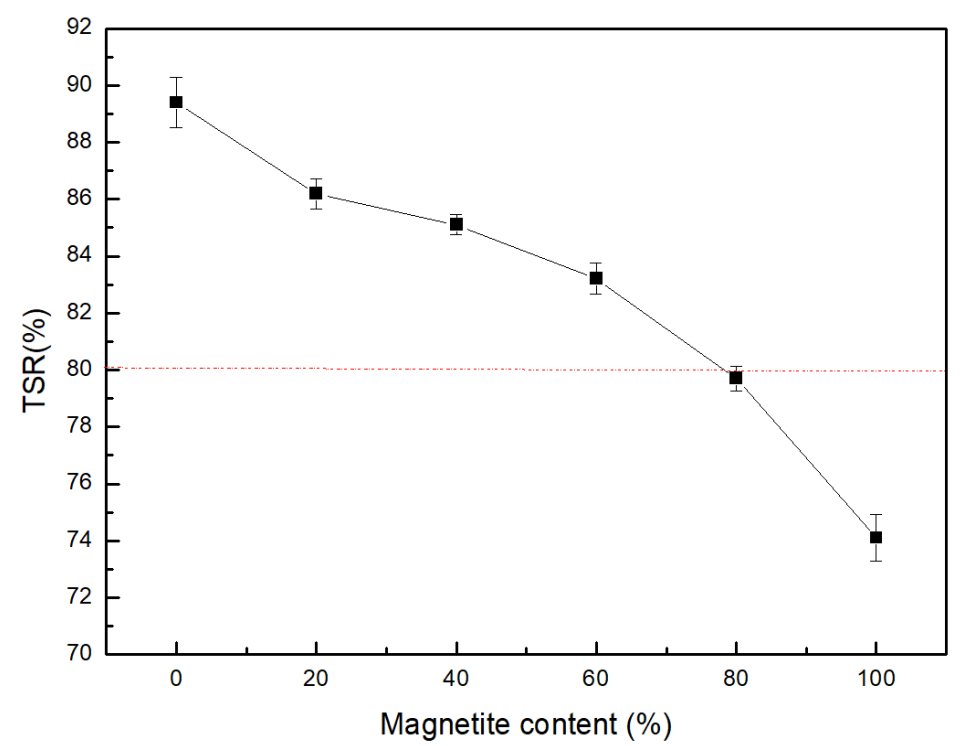

Figure 11. Water sensitivity of different magnetite content. TSR, tensile strength ratio.

\subsection{Effect of MPAM Thickness on the Microwave-Absorbing Performance}

Figure 12 shows the surface temperature of the pavement with different thicknesses of MPAM containing a $60 \%$ dosage of magnetite powders during microwave heating. Table 5 shows a positive linear relationship between surface temperature and microwave heating time of the pavements with different thicknesses of MPAM. Compared with traditional asphalt pavement, the heating rate of the asphalt pavement with 3, 5, and $7 \mathrm{~cm}$ thicknesses of MPAM was increased by $60.3 \%, 34.5 \%$, and $27.2 \%$, respectively. The pavement with $3 \mathrm{~cm}$ thickness of MPAM had the best microwave heating performance.

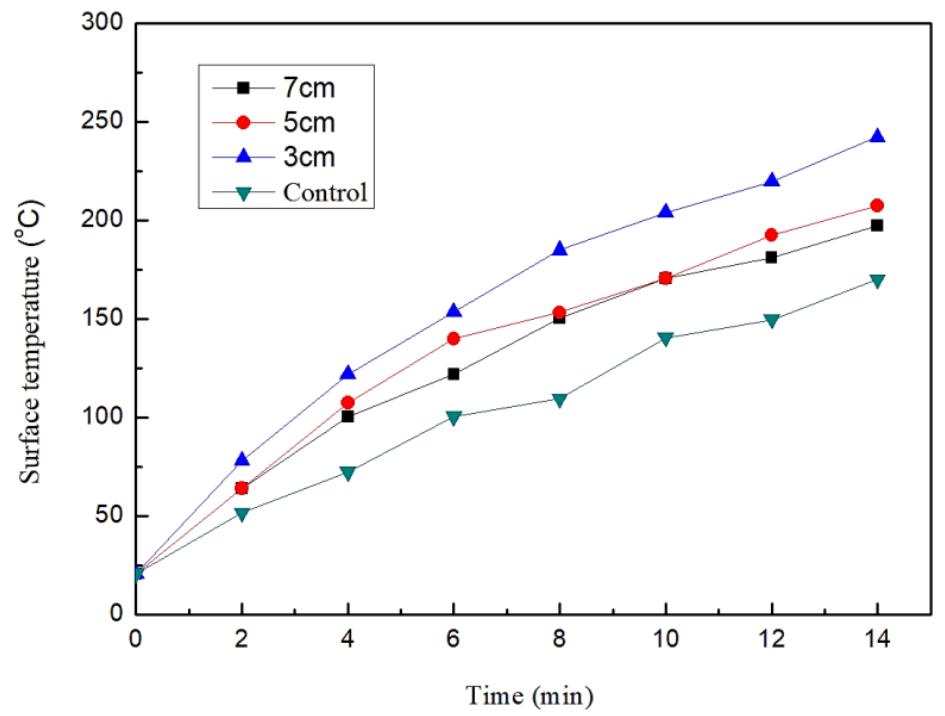

Figure 12. Surface temperature of the pavement with different thicknesses of MPAM.

Table 5. The relationship between surface temperature and heating time.

\begin{tabular}{cccc}
\hline Thickness (cm) & Regression Equation & $\boldsymbol{K}$ & $\boldsymbol{R}^{\mathbf{2}}$ \\
\hline $3 \mathrm{~cm}$ MPAM + 4 cm AM & $T=17.35 t+25$ & 17.35 & 0.985 \\
$4 \mathrm{~cm} \mathrm{MPAM} \mathrm{+} 3$ cm AM & $T=14.55 t+25$ & 14.55 & 0.986 \\
7 cm MPAM & $T=13.76 t+25$ & 13.76 & 0.988 \\
7 cm AM & $T=10.82 t+25$ & 10.82 & 0.966 \\
\hline
\end{tabular}


Figure 13 shows the heating process of pavement with an MPAM layer under microwave heating. When microwaves encounter the pavement, they are transmitted, reflected, and absorbed. The more microwave energy is absorbed, the higher the heating rate of the pavement. Figure 14 shows the reflection losses of the pavement with different thicknesses of MPAM. The greater the absolute value of the reflection loss, the more energy is absorbed, and the more heat is converted. It can be observed from Figure 14 that the pavement with $3 \mathrm{~cm}$ thickness of MPAM had a better absorbing performance than that with 5 and $7 \mathrm{~cm}$ thicknesses of MPAM, which is also proved by Figure 12. This indicates that the absorption efficiency grew with a decrease in the composite layer thickness. It can be inferred that the optimum thickness for microwave absorption may be less than $3 \mathrm{~cm}$. However, the upper layer should be larger than a certain thickness to ensure the durability of the pavement. According to Chinese specification (JTG D50-2017) [34], the thickness of the upper layer made with asphalt mixture with dense gradation should be above $3 \mathrm{~cm}$. Therefore, the upper layer of the microwave-absorbing pavement surface made with asphalt mixture with dense gradation is recommended to be $3 \mathrm{~cm}$ thick in this paper. There are also many new types of pavement surface coatings with thicknesses less than $3 \mathrm{~cm}$, such as ultra-thin friction course and chip seal. These new pavement surface coatings can be designed to achieve an optimum thickness of MPAM. It is also noted that, for $3 \mathrm{~cm} \mathrm{MPAM,} \mathrm{as} \mathrm{the}$ frequency increased, the value of reflection loss first decreased and then increased. There was minimum reflection loss at $13 \mathrm{GHz}$. In summary, the microwave-absorbing properties of MPAM are closely related to its thickness in the pavement structure and frequency of microwaves. Optimal absorbance efficiency can be achieved when a matching thickness of MPAM is subjected to microwave radiation at a matching frequency [35-38]. More work on the matching thickness and matching frequency should be done in future research.

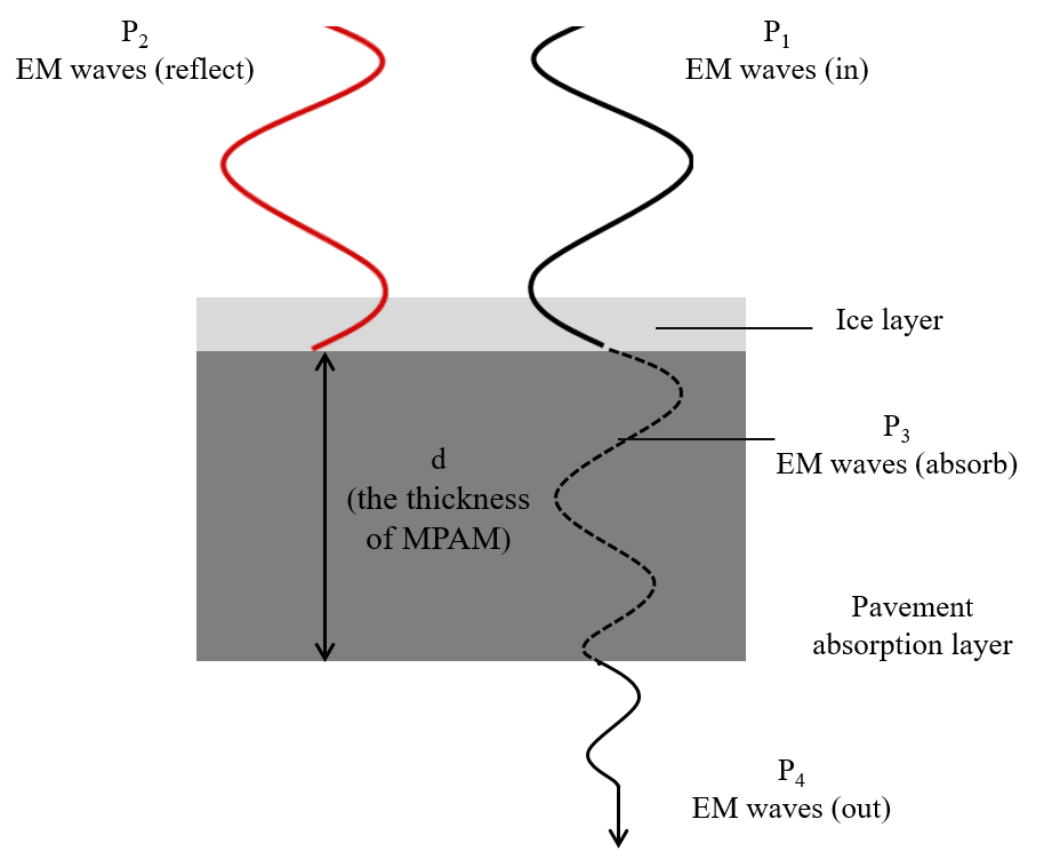

Figure 13. Schematic illustration of EM waves absorption in an asphalt mixture. 


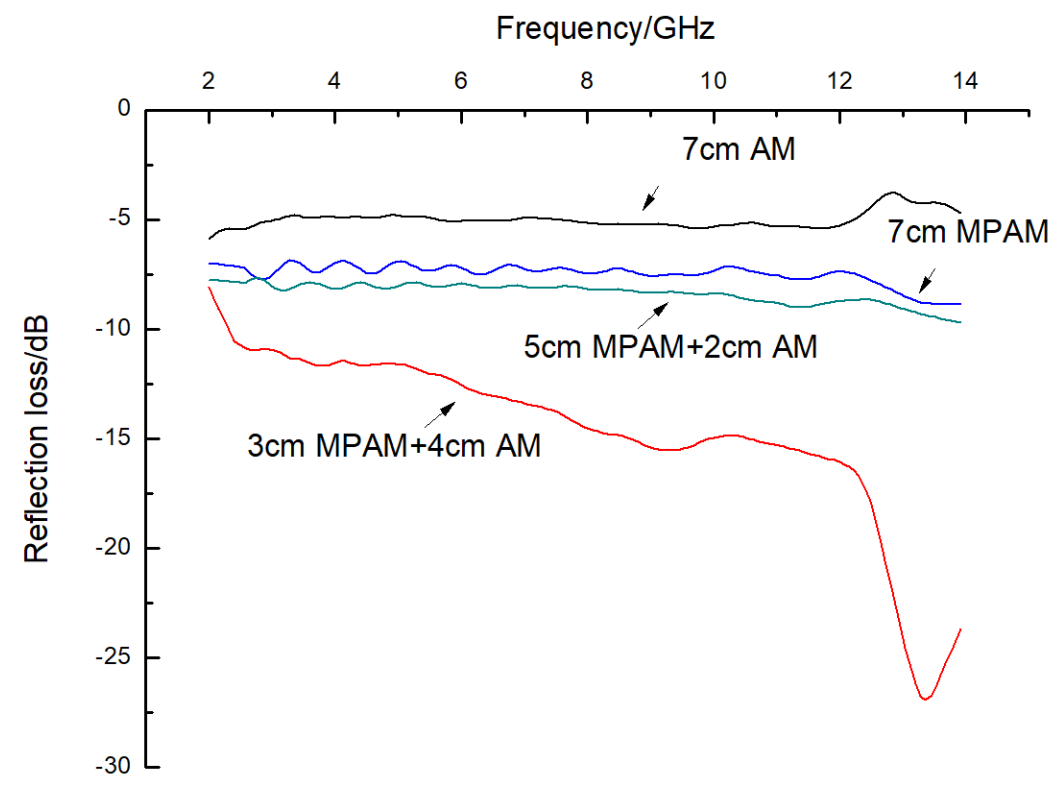

Figure 14. Reflection losses of the pavement with different thicknesses of MPAM.

\section{Conclusions}

- Low microwave absorption efficiency and high cost limit application of the deicing methodology using microwaves. Magnetite powders can be used as inexpensive microwave absorbers to improve the ability of microwave absorption and increase the heating rate of asphalt mixtures. The heating rates of asphalt mixtures increase with the increase of the amount of magnetite powders.

- The addition of magnetite powder improves the low-temperature properties of the asphalt mixture but reduces the water stability of the asphalt mixture.

- Considering that the microwave-absorbing asphalt mixture used for melting snow and ice should also have good water stability, the recommended dosage of magnetite powders is $60 \%$.

- The microwave-absorbing properties of MPAM are related to its thickness in the pavement structure and frequency of microwaves. In order to greatly enhance the absorbing efficiency, future work should be focused on the matching thickness and matching frequency.

Author Contributions: Conceptualization, B.G.; Data curation, J.L. (Jianan Liu) and J.W.; Formal analysis, J.L. (Jingyi Liu) and J.W.; Funding acquisition, B.G. and F.Y.; Investigation, H.Z. and J.L. (Jingyi Liu); Methodology, H.Z. and J.W.; Project administration, B.G.; Resources, B.G.; Software, B.G.; Supervision, B.G.; Validation, H.Z.; Visualization, J.L. (Jianan Liu); Writing-Original draft, J.L. (Jianan Liu), B.G., H.Z. and F.Y.; Writing-Review and editing, B.G.

Funding: The authors wish to thank the financial support from the China Scholarships Council (No. 201806565048); Traffic Innovation Management Consulting Research Project of Yunnan Province (No. 2019304), China Postdoctoral Science Foundation (No. 2019M653520), Natural Science Foundation of Jiangxi Province (20192BBG70064), and Fundamental Research Funds for the Central Universities, CHD (No. 300102319102, No. 300102319202 and No. 3001102319501).

Conflicts of Interest: The authors declare no conflicts of interest.

\section{References}

1. Du, Y.F.; Li, F.J.; Wang, S.Y.; Zhu, X. Inhibition and removal of thin ice on the surface of asphalt pavements by hydrophobic method. J. Insp. Eval. 2016, 44,711-718. [CrossRef]

2. Fay, L.; Shi, X.M. Environmental impacts of chemicals for snow and ice control: state of the knowledge. Water Air Soil Pollut. 2012, 223, 2751-2770. [CrossRef] 
3. Vo, H.V.; Park, D.W.; Dessouky, S. Simulation of snow melting pavement performance using measured thermal properties of graphite-modified asphalt mixture. Road Mater. Pavement Des. 2015, 16, 696-706. [CrossRef]

4. Hassan, Y.; Halim, A.O.A.E.; Razaqpur, A.G.; Bekheet, W.; Farha, M.H. Effects of runway deicers on pavement materials and mixes: Comparison with road salt. J. Trans. Eng. 2002, 128, 385-391. [CrossRef]

5. Benedetto, A.; Calvi, A. A pilot study on microwave heating for production and recycling of road pavement materials. Constr. Build. Mater. 2013, 44, 351-359. [CrossRef]

6. Liu, Q.T.; Schlangen, E.; García, Á.; van de Ven, M. Induction heating of electrically conductive porous asphalt concrete. Constr. Build. Mater. 2010, 24, 1207-1213. [CrossRef]

7. Wang, Z.G.; Dai, Q.L.; Porter, D.; You, Z.P. Investigation of microwave healing performance of electrically conductive carbon fiber modified asphalt mixture beams. Constr. Build. Mater. 2016, 126, 1012-1019. [CrossRef]

8. Gao, J.; Zhang, Z.W.; Han, Z.Q.; Sha, A.M.; Wang, Z.J.; Jiang, W. A review of electromagnetic wave absorbing materials used in microwave deicing pavement. Mater. Rev. 2016, 30, 87-95. [CrossRef]

9. Meng, F.B.; Wang, H.G.; Huang, F.; Guo, Y.F.; Wang, Z.Y.; Hui, D.; Zhou, Z.W. Graphene-based microwave absorbing composites: A review and prospective. Compos. Part B Eng. 2018, 137, 260-277. [CrossRef]

10. Liu, J.L.; Xu, J.Y.; Lu, S.; Chen, H.W. Investigation on dielectric properties and microwave heating efficiencies of various concrete pavements during microwave deicing. Constr. Build. Mater. 2019, 225, 55-66. [CrossRef]

11. Norambuena-Contreras, J.; Gonzalez-Torre, I. Influence of the microwave heating time on the self-healing properties of asphalt mixtures. Appl. Sci. 2017, 7, 1076. [CrossRef]

12. Wang, Z.J.; Wang, H.F.; An, D.D.; Ai, T.; Zhao, P. Laboratory investigation on deicing characteristics of asphalt mixture using magnetite aggregate as microwave-absorbing materials. Constr. Build. Mater. 2016, 124, 589-597. [CrossRef]

13. Sun, Y.H.; Wu, S.P.; Liu, Q.T.; Hu, J.F.; Yuan, Y.; Ye, Q.S. Snow and ice melting properties of self-healing asphalt mixture with induction heating and microwave heating. Appl. Therm. Eng. 2017, 129, 871-883. [CrossRef]

14. Gao, J.; Sha, A.M.; Wang, Z.J.; Tong, Z.; Liu, Z.Z. Utilization of steel slag as aggregate in asphalt mixture for microwave deicing. J. Clean. Prod. 2017, 152, 429-442. [CrossRef]

15. Notani, M.A.; Arabzadeh, A.; Ceylan, H.; Kim, S.; Gopalakrishnan, K. Effect of carbon-fiber properties on volumetrics and ohmic heating of electrically conductive asphalt concrete. J. Mater. Civ. Eng. 2019, 31, 04019200. [CrossRef]

16. Sun, Y.H.; Wu, S.P.; Liu, Q.T.; Zeng, W.B.; Chen, Z.W.; Ye, Q.S.; Pan, P. Self-healing performance of asphalt mixtures through heating fibers or aggregate. Constr. Build. Mater. 2017, 150, 673-680. [CrossRef]

17. Zhang, J.F.; Yan, Y.; Hu, Z.H.; Fan, X.Z.; Zheng, Y. Utilization of low-grade pyrite cinder for synthesis of microwave heating ceramics and their microwave deicing performance in dense-graded asphalt mixture. J. Clean. Prod. 2017, 170, 486-495. [CrossRef]

18. Wang, Y.D.; Liu, Z.M.; Hao, P.W. Investigation on mechanical and microwave heating characteristics of asphalt mastic using activated carbon powder as electro-magnetic absorbing materials. Constr. Build. Mater. 2019, 202, 692-703. [CrossRef]

19. Guan, B.W.; Ding, D.H.; Wang, L.F.; Wu, J.Y.; Xiong, R. The electromagnetic wave absorbing properties of cement-based composites using natural magnetite powders as absorber. Mater. Res. Express 2017, 4, 056103. [CrossRef]

20. ASTM D5/D5M-19-Standard Test Method for Penetration of Bituminous Materials; ASTM International: West Conshohocken, PA, USA, 2019.

21. ASTM D36/D36M-14e1-Standard Test Method for Softening Point of Bitumen (Ring-and-Ball Apparatus); ASTM International: West Conshohocken, PA, USA, 2014.

22. ASTM D113-17—Standard Test Method for Ductility of Asphalt Materials; ASTM International: West Conshohocken, PA, USA, 2017.

23. ASTM D3344-90(2015)—Standard Test Method for Total Wax Content of Corrugated Paperboard; ASTM International: West Conshohocken, PA, USA, 2015.

24. ASTM D70-18a-Standard Test Method for Density of Semi-Solid Asphalt Binder (Pycnometer Method); ASTM International: West Conshohocken, PA, USA, 2018.

25. ASTM D92-18-Standard Test Method for Flash and Fire Points by Cleveland Open Cup Tester; ASTM International: West Conshohocken, PA, USA, 2018. 
26. ASTM D2872-19—Standard Test Method for Effect of Heat and Air on a Moving Film of Asphalt (Rolling Thin-Film Oven Test); ASTM International: West Conshohocken, PA, USA, 2019.

27. Standard Test Methods of Asphalt and Asphalt Mixtures for Highway Engineering, JTG E20; MOT: Beijing, China, 2011. (In Chinese)

28. The Measurement Methods the Reflectivity of Radar Absorbing Materia, GJB 2038Al; CPLAGED: Beijing, China, 2011. (In Chinese)

29. Hardianto, Y.P.; Taufiq, A.; Hidayat, A.; Sunaryono, S.; Listanti, A.; Wisodo, H. Nanostructure analysis for microwave absorption properties of $\mathrm{Fe}_{3} \mathrm{O}_{4}$ particles by symmetry top rotational molecular model. IOP Conf. Ser. Mater. Sci. Eng. 2018, 167, 012009. [CrossRef]

30. Wang, Z.J.; Xu, C.; Wang, S.; Gao, J.; Ai, T. Utilization of magnetite tailings as aggregates in asphalt mixtures. Constr. Build. Mater. 2016, 114, 392-399. [CrossRef]

31. Liu, Z.M.; Yang, X.; Wang, Y.D.; Luo, S. Engineering properties and microwave heating induced ice-melting performance of asphalt mixture with activated carbon powder filler. Constr. Build. Mater. 2019, 197, 50-62. [CrossRef]

32. Ziari, H.; Divandari, H.; Hajiloo, M.; Amini, A. Investigating the effect of amorphous carbon powder on the moisture sensitivity, fatigue performance and rutting resistance of rubberized asphalt concrete mixtures. Constr. Build. Mater. 2019, 217, 62-72. [CrossRef]

33. Technical Specification for Construction of Highway Asphalt Pavements in China, JTG F40; MOT: Beijing, China, 2004. (In Chinese)

34. Specification for Design of Highway Asphalt Pavement, JTG D50-2017; MOT: Beijing, China, 2017. (In Chinese)

35. Ding, D.H.; Shi, Y.M.; Wu, Z.H. Electromagnetic interference shielding and dielectric properties of $\mathrm{SiC}_{\mathrm{f}} / \mathrm{SiC}$ composites containing pyrolytic carbon interphase. Carbon 2013, 60, 552-555. [CrossRef]

36. Ding, D.H.; Luo, F.; Zhou, W.C. Effects of thermal oxidation on electromagnetic interference shielding properties of $\mathrm{SiCf} / \mathrm{SiC}$ composites. Ceram. Int. 2013, 39, 4281-4286. [CrossRef]

37. Ding, D.; Wang, J.; Yu, X.; Xiao, G.; Feng, C.; Xu, W.; Bai, B.; Yang, N.; Gao, Y.; Hou, X.; et al. Dispersing of functionalized CNTs in $\mathrm{Si}-\mathrm{O}-\mathrm{C}$ ceramics and electromagnetic wave absorbing and mechanical properties of CNTs/Si-O-C nanocomposites. Ceram. Int. 2019. [CrossRef]

38. Ding, D.; Wang, J.; Xiao, G.; Li, Z.; Bai, B.; Ren, J.; He, G. Enhanced electromagnetic wave absorbing properties of Si-O-C ceramics with in-situ formed 1D nanostructures. Int. J. Appl. Ceram. Technol. 2019. [CrossRef] 